\title{
A Study on the Bond Strength between High Performance Concrete and Reinforcing Bar
}

\author{
Eun Suk Choi, Jung Woo Lee, Seong Jun Kim, Jong Won Kwark \\ Korea Institute of Civil Engineering and Building Technology, Goyang, Republic of Korea \\ Email: eschoi@kict.re.kr, duckhawk@kict.re.kr, seongjun@kict.re.kr, origilon@kict.re.kr
}

Received 9 June 2015; accepted 11 July 2015; published 14 July 2015

Copyright $@ 2015$ by authors and Scientific Research Publishing Inc.

This work is licensed under the Creative Commons Attribution International License (CC BY). http://creativecommons.org/licenses/by/4.0/

(c) () Open Access

\begin{abstract}
As a preliminary study for the erection of floating structures using high performance concrete, this paper examines the bond characteristics between concrete and the reinforcing bar. Since the floating structure is constructed in aquatic environment, corrosion of the reinforcing steel is likely to develop more prematurely than in onshore structure in case of concrete cracking. A solution to this corrosion problem could use FRP rebar instead of steel reinforcement. To that goal, an experimental study is conducted on the concrete-FRP bond strength to verify if such FRP rebar develops performance comparable to the conventional steel rebar. A series of tests are performed considering the bond length of ordinary steel rebar and G-FRP rebar as test variable with respect to the strength of concrete, and the results are presented.
\end{abstract}

\section{Keywords}

FRP Reinforcement, High Performance Concrete, Bond Strength, Concrete Strength, Bond Length

\section{Introduction}

The existing steel floating structures are exposed to the specific environmental problems encountered by large marine structures including corrosion and the need for periodic repainting to prevent corrosion. Besides, the existing concrete floating structures are prone to problems like the increased height of the structure to secure the buoyancy necessary to lift the excessive weight of the structure and the corrosion of inner reinforcement caused by the intrusion of seawater provoked by the lack of watertightness.

An alternative to cope with this corrosion problem could replace the conventional steel reinforcement arranged in concrete by GFRP bars. Therefore, a series of tests are conducted to evaluate the bond performance between concrete and GFRP. Numerous results have been reported on the bond performance between concrete and the reinforcing steel, and studies have been and are still being conducted on the bond between concrete and 
FRP [1] [2]. For example, Habel [3] carried out a study on the bond strength and control of cracks between the steel reinforcement and concrete by the fiber reinforcement in ultra high performance concrete (UHPC). And, Holschemacher et al. [4] studied the bond strength according to the age of UHPC, the diameter of rebar, the thickness of cover and the loading speed.

As a preliminary study for the application of SUPER Concrete (SC, compressive strength range: 80 - 180 $\mathrm{MPa}$ ), the high performance concrete developed by the Korea Institute of Civil Engineering and Building Technology (KICT), to floating structures, this paper examines experimentally the bond performance between SC and conventional reinforcing steel, and between SC and GFRP bar. To that goal, tests are performed on specimens fabricated taking the compressive strength of the concrete member, the bond length and the type of reinforcing bar as test variables.

\section{Bond Test}

Bond strength tests are performed considering the strength of concrete and bond length of the reinforcement as test variables to evaluate the bond strength between concrete and the reinforcing bar at the intersegmental connection of the floating structure using SC. For the tests, the diameter of the steel and FRP bars is set to $10 \mathrm{~mm}$, and the target strength of concrete is set to 40, 80, 100, and $120 \mathrm{MPa}$. Loading is applied at speed of $1.3 \mathrm{~mm} / \mathrm{min}$ and, the bond length is varied as $40,70,100$, and $130 \mathrm{~mm}$.

The evaluation of the bond characteristics between SC and the reinforcement is conducted by modifying partially the test method recommended by RILEM (International Union of Laboratories and Experts in Construction Materials, Systems and Structures) [5]. RILEM proposes to use cubic specimens with side length being the minimum between $200 \mathrm{~mm}$ and $10 d_{s}$, where $d_{s}$ is the diameter of rebar. In this study, it was considered that the minimum length of $200 \mathrm{~mm}$ is appropriate for ordinary strength concrete. Accordingly, the concrete cube specimens were fabricated with side length of $200 \mathrm{~mm}$ and were steel-reinforced to prevent failure of concrete before the occurrence of bond failure as shown in Figure 1. Table 1 lists the types of the specimens and the corresponding test variables. Figure 2 displays the disposition of the specimens and deflectometers.
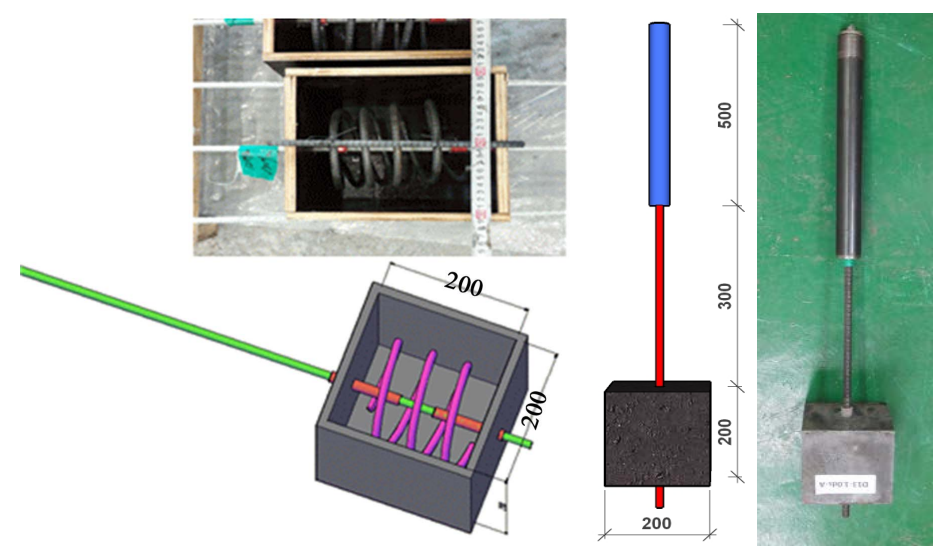

Figure 1. Shape of specimen.

Table 1. Type of specimens and corresponding test variables.

\begin{tabular}{|c|c|c|c|c|}
\hline & Reinforcement & Concrete compressive strength (MPa) & Bond length (mm) & Number of specimens \\
\hline \multirow[t]{3}{*}{ Steel } & D10 ( $\phi 10$-steel) & $40,80,100,120$ & 40 & 5 ea. per strength \\
\hline & & 40 & $40,70,100,130$ & 5 ea. per length \\
\hline & & 80 & $40,70,100,130$ & 5 ea. per length \\
\hline \multirow{3}{*}{ GFRP } & D9.5 (ф9.5-GFRP) & 100 & $40,70,100,130$ & 5 ea. per length \\
\hline & & 120 & $40,70,100,130$ & 5 ea. per length \\
\hline & & & Total & 100 \\
\hline
\end{tabular}



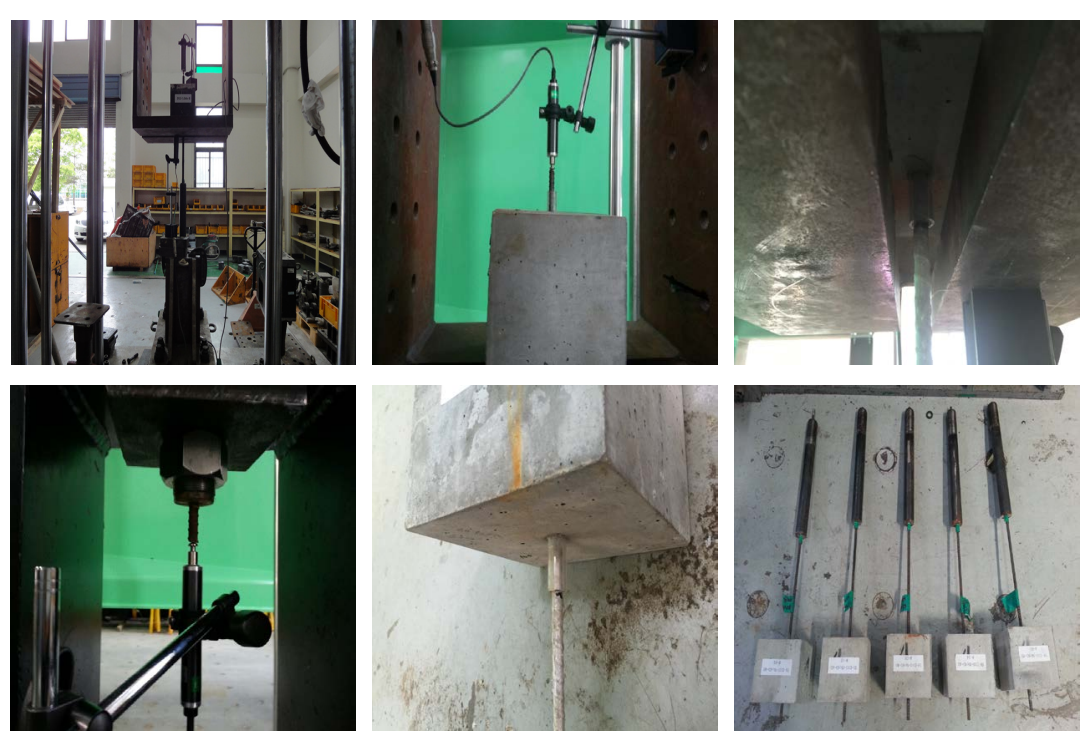

Figure 2. View of specimens and layout of deflectometers.

As shown in Figure 2, a deflectometer is installed at each top, center and bottom to measure respectively the concrete-reinforcement displacement, the relative displacement between concrete and the anchorage, and the displacement of the anchorage.

Figure 3 plots the deflection history caused by the bond failure of the reinforcement with respect to the applied load for the concrete compressive strength of $40 \mathrm{MPa}$. In Figure 3, clear difference can be observed in the behavior of steel reinforcement (Figure 3(a) and Figure 3 (b)) and GFRP reinforcement (Figure 3(c) and Figure 3(d)). In Figure 3, DT-1 plots the response measured by the deflectometer installed at the top and represents the relative displacement between the concrete block and the reinforcement, DT-2 is the relative displacement between the concrete block and the anchorage, DT-3 is the absolute displacement of the anchorage and, UTM stands for the actual displacement of the UTM (Universal Testing Machine). For curve DT-1 showing the bond performance, clear difference can be identified in the behavior of the steel reinforcement and GFRP. Concretely, the relative displacement between the concrete block and the steel reinforcement increases linearly until brittle bond failure whereas the relative displacement between the concrete block and GFRP starts with a linear increase to show ductile bond failure. Besides, curve DT-2 shows identical pattern to that of UTM. Especially, the part in which the slope of the curve varies indicates simultaneous occurrence of bond failure and tensile failure of the steel reinforcement.

\section{Test Results}

The average bond stress $\tau$ at any stage during loading is calculated using Equation (1).

$$
\tau=\frac{P}{\pi d_{b} l_{b}}
$$

where $P$ is the pullout load, $d_{b}$ is the diameter of the rebar, and $l_{b}$ is the embedment length of the rebar.

Table 2 arranges the bond test results of the steel and GFRP reinforcement. Figure 4 plots the hysteresis of the bond force per strength of concrete. It can be seen that the bond force of the steel reinforcement keeps a constant level even when the strength of the block increases. Besides, the bond force of the GFRP reinforcement increases with higher strength of the block and longer bond length as expected.

Figure 5 plots the bond force with respect to the compressive strength of concrete and bond length. The bond strength of the steel reinforcement is seen to range between 35 and 37 MPa and that of the GFRP rebar between 15 and $21 \mathrm{MPa}$. For the GFRP reinforcement, it was expected that the bond stress would increase proportionally to the increase of the strength of concrete and bond length but the strength appeared to keep a definite level without steep increase. This result can be explained by the occurrence of failure due to the cover of the GFRP itself prior to the bond failure according to the lengthening of the bond length between the concrete block and 


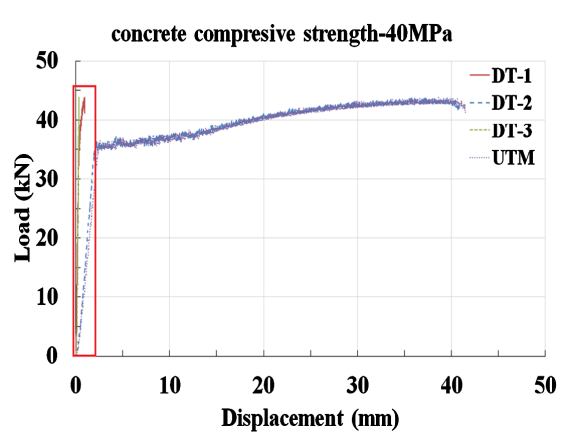

(a)

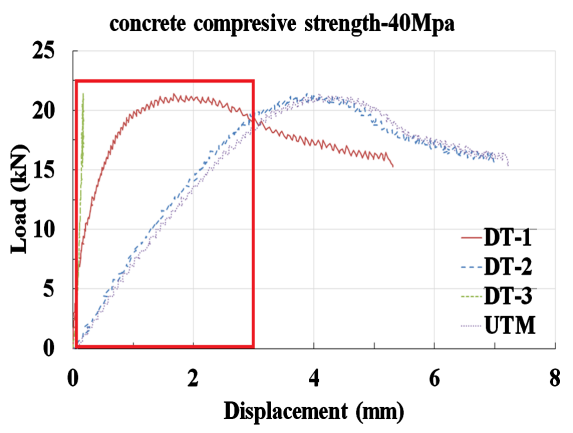

(c)

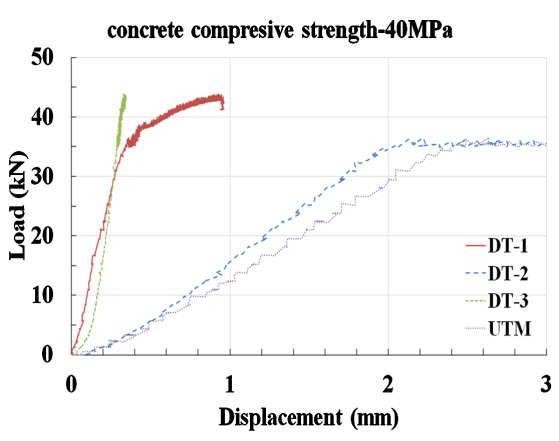

(b)

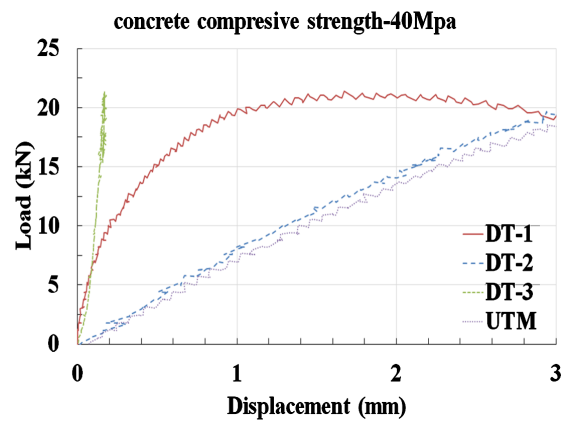

(d)

Figure 3. Comparison of experimental bond performance between steel and GFRP reinforcement. (a) Concrete-steel rebar load-displacement curves; (b) Zoom up of (A); (c) Concrete-GFRP rebar load-displacement curves; (d) Zoom up of (B).

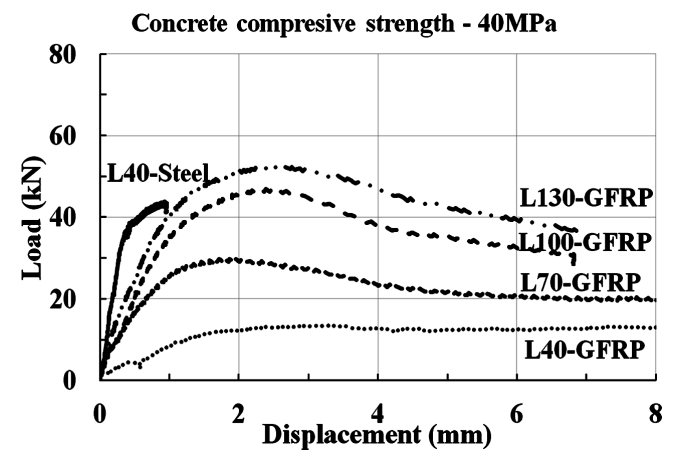

(a)

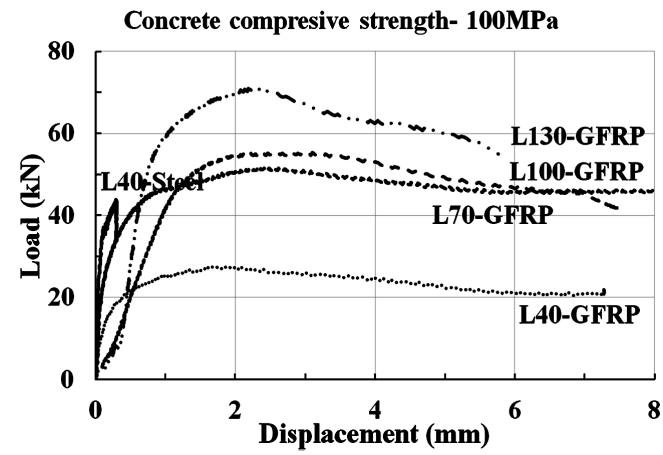

(c)

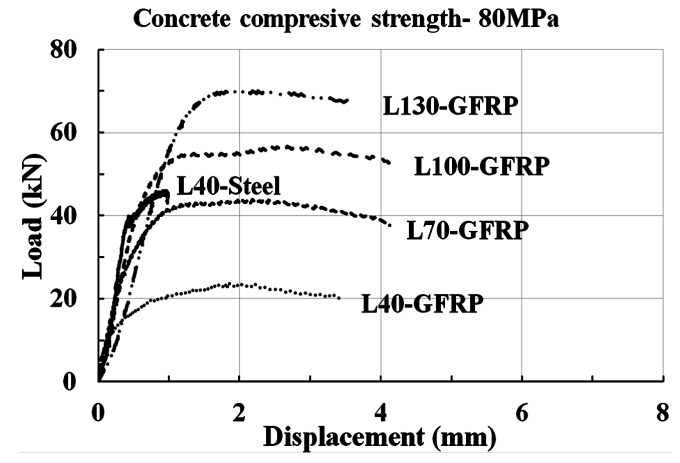

(b)

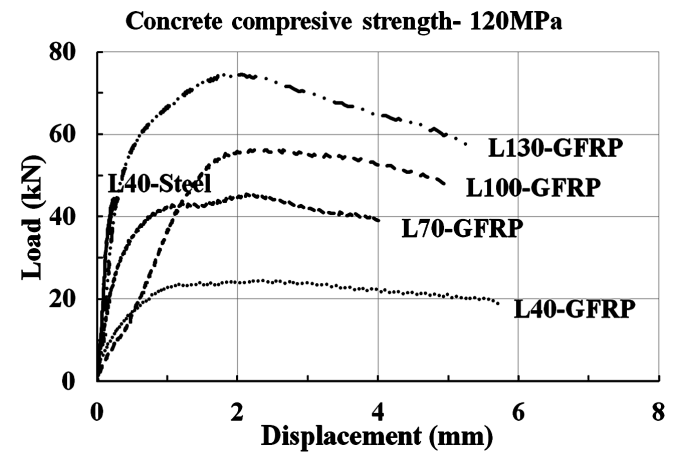

(d)

Figure 4. Bond force-deflection hysteresis per compressive strength of concrete. (a) Concrete compressive strength of 40 MPa; (b) Concrete compressive strength of $80 \mathrm{MPa}$; (c) Concrete compressive strength of $100 \mathrm{MPa}$; (d) Concrete compressive strength of $120 \mathrm{MPa}$. 
Concrete compresive strength-40MPa

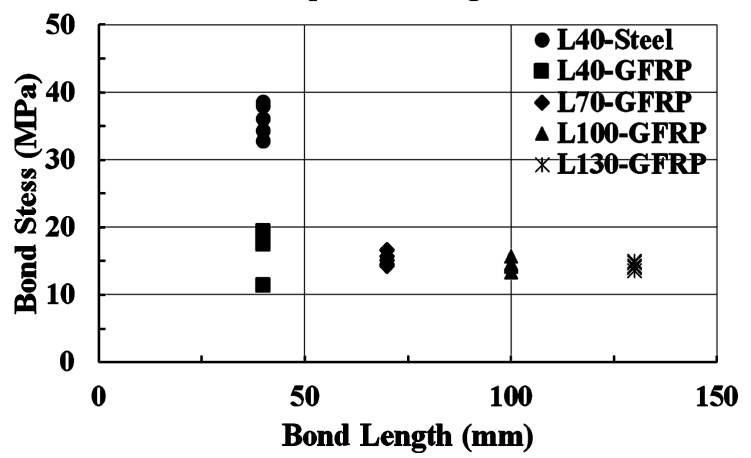

(a)

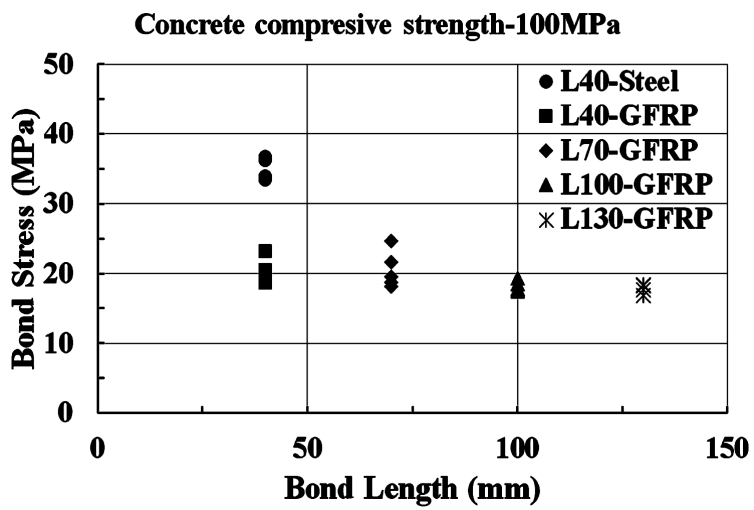

(c)

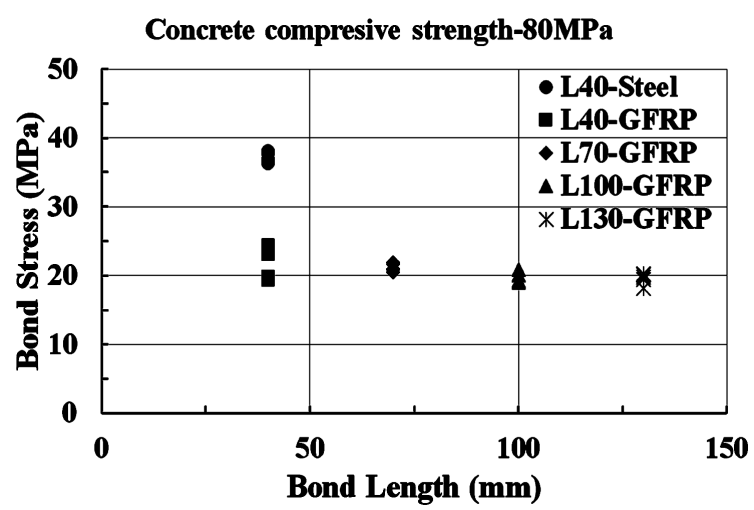

(b)

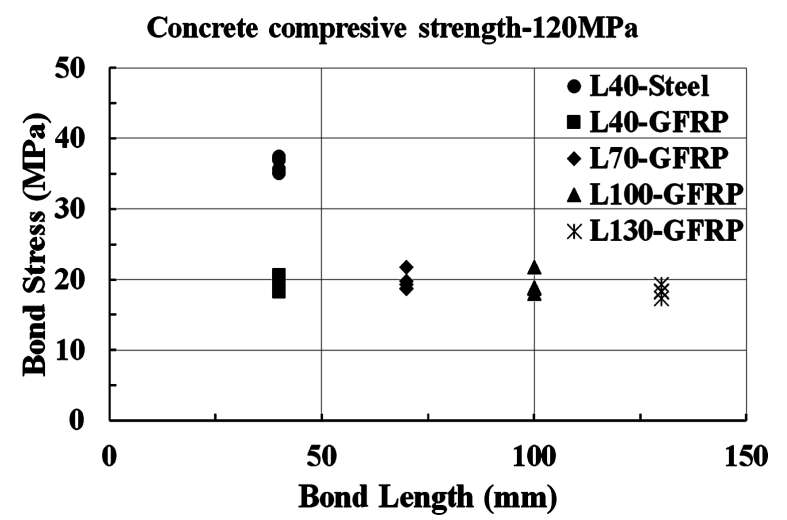

(d)

Figure 5. Bond stress-bond length relation per compressive strength of concrete. (a) Concrete compressive strength of 40 MPa; (b) Concrete compressive strength of $80 \mathrm{MPa}$; (c) Concrete compressive strength of $100 \mathrm{MPa}$; (d) Concrete compressive strength of $120 \mathrm{MPa}$.

Table 2. Bond strength (average).

\begin{tabular}{|c|c|c|c|c|c|c|c|c|c|}
\hline \multirow{2}{*}{$\begin{array}{l}\text { Rebar } \\
\text { type }\end{array}$} & \multirow{2}{*}{$\begin{array}{l}\text { Compr. } \\
\text { strength of } \\
\text { concrete } \\
(\mathrm{MPa})\end{array}$} & \multicolumn{2}{|r|}{$4 d_{s}$} & \multicolumn{2}{|r|}{$7 d_{s}$} & \multicolumn{2}{|c|}{$10 d_{s}$} & \multicolumn{2}{|c|}{$13 d_{s}$} \\
\hline & & $\begin{array}{c}\text { Max. } \\
\operatorname{load}(\mathrm{kN})\end{array}$ & $\begin{array}{c}\text { Bond } \\
\text { strength }(\mathrm{MPa})\end{array}$ & $\begin{array}{l}\text { Max. load } \\
\quad(\mathrm{kN})\end{array}$ & $\begin{array}{l}\text { Bond strength } \\
\text { (MPa) }\end{array}$ & $\begin{array}{l}\text { Max. load } \\
\quad(\mathrm{kN})\end{array}$ & $\begin{array}{l}\text { Bond strength } \\
\qquad(\mathrm{MPa})\end{array}$ & $\begin{array}{l}\text { Max. load } \\
(\mathrm{kN})\end{array}$ & $\begin{array}{l}\text { Bond strength } \\
\text { (MPa) }\end{array}$ \\
\hline \multirow{4}{*}{ Steel } & 40 & 43.068 & 35.89 & & & & & & \\
\hline & 80 & 44.552 & 37.13 & & & & & & \\
\hline & 100 & 42.392 & 35.33 & & & & & & \\
\hline & 120 & 43.698 & 36.42 & & & & & & \\
\hline \multirow{4}{*}{ GFRP } & 40 & 20.206 & 16.93 & 31.852 & 15.25 & 43.118 & 14.45 & 55.596 & 14.34 \\
\hline & 80 & 25.302 & 21.21 & 44.210 & 21.17 & 59.204 & 19.85 & 75.890 & 19.57 \\
\hline & 100 & 23.978 & 20.10 & 42.876 & 20.53 & 54.116 & 18.14 & 69.430 & 17.90 \\
\hline & 120 & 23.486 & 19.68 & 41.074 & 19.67 & 57.450 & 19.26 & 71.104 & 18.34 \\
\hline
\end{tabular}

GFRP reinforcement. Therefore, it seems that GFRP does not experience significant change when the critical bond length is secured even under increase of the bond length and compressive strength of concrete.

\section{Conclusion}

As part of a research for the erection of floating structures using high performance concrete, this paper presented a preliminary experimental study on the bond characteristics between concrete and the reinforcing bar. Tests were performed to verify the performance of steel and GFRP reinforcements taking the compressive strength of concrete and the bond length as test variables. For the steel rebar, tensile failure of the reinforcement occurred before bond failure since sufficient bond length was applied. Therefore, it appeared that the bond performance 
of the steel reinforcement was secured. For the GFRP rebar, it was verified that the cover of GFRP failed prior to the bond failure even under increase of the bond length and compressive strength of concrete, because the specimens secured sufficient bond length. Additional study on the critical bond length of GFRP should be conducted in the future.

\section{Acknowledgements}

This research was supported by a grant (14 AUDP-B069364-02) from Urban Architectural Research Program funded by Ministry of Land, Infrastructure and Transport of Korean Government.

\section{References}

[1] Korea Institute of Construction Technology (KICT) (2009) Design Specific Technology for Ultra High Performance Concrete. Report of $2^{\text {nd }}$ Year of Super Bridge 2020, 135-155.

[2] Habel, K. (2004) Structural Behaviour of Elements Combining Ultra-High Performance Fibre Reinforced Concrete (UHPFRC) and Reinforced Concrete. Doctoral Thesis No. 3036, EPFL Swiss Federal Institute of Technology, Lausanne.

[3] Park, J.-H., Kim, J.-S. and Joh, C.-B. (2014) An Experimental on Bond Behavior of UHPC Using Pull-Out Test. Proceedings of the Korea Concrete Institute, 26, 543-544.

[4] Holschemacher, K., Weiße, D. and Klotz, S. (2004) Bond of Reinforcement in Ultra High Strength Concrete. Proceedings of the $2^{\text {nd }}$ International Symposium in Ultra High Performance Concrete, Kassel, September 2004, 375-388.

[5] RILEM (1970) Bond Test for Reinforcing Steel: 2. Pullout Test. Recommendation RC 6. 